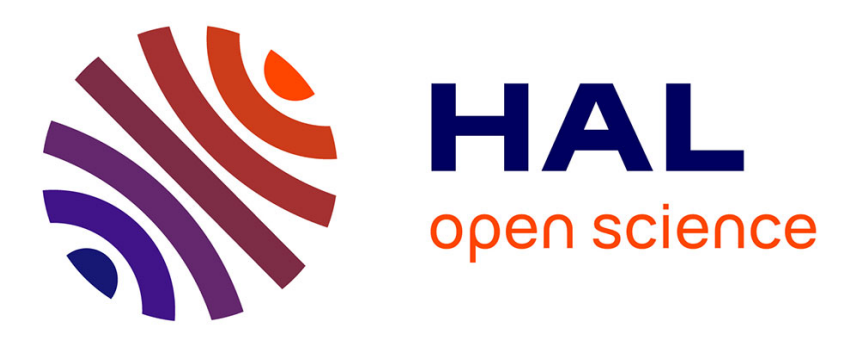

\title{
Design and Characterization of a CPSS-based Unit-Cell for Circularly Polarized Reflectarray Applications
} Simon Mener, Raphaël Gillard, Ronan Sauleau, Cécile Cheymol, Patrick Potier

\section{- To cite this version:}

Simon Mener, Raphaël Gillard, Ronan Sauleau, Cécile Cheymol, Patrick Potier. Design and Characterization of a CPSS-based Unit-Cell for Circularly Polarized Reflectarray Applications. IEEE Transactions on Antennas and Propagation, 2013, 61 (04), pp.MENER. hal-00771343

\section{HAL Id: hal-00771343 https://hal.science/hal-00771343}

Submitted on 8 Jan 2013

HAL is a multi-disciplinary open access archive for the deposit and dissemination of scientific research documents, whether they are published or not. The documents may come from teaching and research institutions in France or abroad, or from public or private research centers.
L'archive ouverte pluridisciplinaire HAL, est destinée au dépôt et à la diffusion de documents scientifiques de niveau recherche, publiés ou non, émanant des établissements d'enseignement et de recherche français ou étrangers, des laboratoires publics ou privés. 


\title{
Design and Characterization of a CPSS-based Unit-Cell for Circularly Polarized Reflectarray Applications
}

\author{
Simon Mener, Raphael Gillard, Ronan Sauleau, Senior Member, IEEE, Cecile Cheymol, Patrick Potier
}

\begin{abstract}
A CPSS-based unit-cell is proposed as a building block of future reconfigurable dual-CP reflectarrays illuminated by a dual CP primary feed. It is based on an enhanced version of the original Pierrot's cell with multiple wires bent in a crank-like shape. It provides a 2-bit phase resolution in reflection for the left hand circular polarization (LHCP) and is nearly transparent in right hand circular polarization (RHCP). The main design steps and measurement procedure of the optimized cell are described in detail. The simulated and measured characteristics are in good agreement. The experimental results demonstrate a $6.4 \%$ bandwidth for a phase resolution better than 1.9bits and an insertion loss of $0.5 \mathrm{~dB}$ at resonance.
\end{abstract}

Index Terms - Circular polarization selective surface, reflectarray, unit-cell.

\section{INTRODUCTION}

$\mathrm{R}^{\mathrm{k}}$ ECONFIGURABLE reflectarrays [1] are very attractive for beam-scanning or beam-shaping in space applications such as Earth observations and satellite communications. They combine the benefits of active phased arrays and reflector antennas, thus leading to high-performance multiple-beam antenna systems. In order to achieve higher data rate transmissions and prevent from losses due to polarization misalignment, circular polarization (CP) is usually preferred. Several circularly polarized reflectarray unit-cells in frozen states have been proposed in the literature using either a linearly-polarized incident wave [2] or a circularly polarized one [3]. Reconfigurable CP reflectarray unit-cells have been also studied [4], [5]; but they only operate with one single CP wave. To our best knowledge, reconfigurable dual-CP unit-cells with independent control of the reflected phases in both polarizations have never been studied so far. On the other hand, circular polarization selective surfaces (CPSS) have been

Manuscript received March 16, 2012. This work was supported in part by the Centre National d'Etudes Spatiales (CNES) and in part by the Direction Générale de l'Armement (DGA).

S. Mener and R. Gillard are with the Institute of Electronics and Telecommunications of Rennes, European University of Brittany, INSA, UMR CNRS 6164, 35708 Rennes (e-mail : simon.mener@insa-rennes.fr).

R. Sauleau is with the Institute of Electronics and Telecommunications of Rennes, University of Rennes 1, UMR CNRS 6164, 35042 Rennes (ronan.sauleau@univ-rennes1.fr).

C. Cheymol is with the French space agency CNES, 31401, Toulouse CEDEX 9, France (cecile.cheymol@cnes.fr).

P. Potier is with the DGA Maîtrise de l'information, BP 57419, 35174, Bruz CEDEX, France (patrick.potier@dga.defense.gouv.fr). widely studied to separate RHCP and LHCP waves by reflecting one polarization and transmitting the other one. Different potential applications of the CPSS unit-cells for reflector antennas are reported in [6] and for which reconfigurability would be of great benefit. Typically, CPSS may be used to reduce sub-reflector blockage in dual reflector antennas, to implement frequency-reuse through polarization diversity or to design a mirror antenna for circular polarization. Historically, the first CPSS was proposed by Pierrot in 1966 [7]. The theoretical proof of existence of the ideal CPSS and first numerical results were given by Roy and Shafai [8]. Experimental validations can be found in [9], [10]. CPSS can be used also as polarization converter [11], but have never been applied for reflectarray applications. On the other hand, it is well know that the Pierrot's cell is very sensitive to the oblique incidence. To circumvent this limitation, several solutions have been reported, either to limit incidence angle on reflectarrays cells (for instance using a larger $F / D$ ratio or a facetted configuration as in [12]) or to improve the robustness of the cell to incident angle [13]. In the proposed configuration where the cell is backed by a metallic cavity and covered by a metallic grid, the angle of incidence should not exceed $20^{\circ}$ to prevent from both parasitic reflection and polarization conversion.

In this paper, we suggest to use a reconfigurable CPSS-based unit-cell as a building block of future reconfigurable dual-CP reflectarrays illuminated by a dual-CP primary feed. A schematic view of the proposed concept is represented in Fig. 1a. The future reflectarray panel will be made of two layers: the first one (layer-1) reflects the incident LHCP wave and is based on left-hand CPSS (LH-CPSS) unit-cells (Fig. 1b), whereas the second layer (layer-2) is designed to reflect the RHCP incident wave. It is worthwhile to mention that layer-2 can be made of conventional CP unit-cells (e.g. [14]) as it is illuminated by a single CP incident wave. Therefore, in this paper, we focus our attention on the unit-cell of layer-1 only. Deriving a full dual$\mathrm{CP}$ cell would require additional optimization steps in order to comply with the $25 \mathrm{~dB}$ cross-polarization rejection specified for our future application which is not addressed in this paper. Ideally, the unit-cell of layer-1 is designed and optimized to achieve simultaneously i) a total and broadband reflection with a 2-bit phase resolution for the LHCP polarization and ii) a perfect transmission for the RHCP polarization. The four achieved phase states are labelled State 1 to State 4. As done in [15], in the proposed design, the cell is embedded in a square metallic cavity (Fig. 1b) in order to reduce mutual coupling 
between neighbouring unit-cells. In this paper, we thus present the design steps and performance for this first layer.

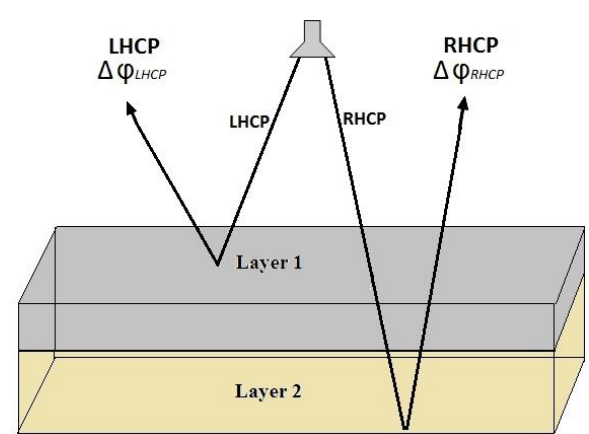

(a)

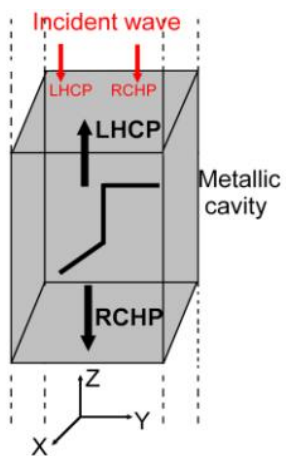

(b)
Fig. 1. (a) Schematic representation of a future reflectarray with independent control of both incident circular polarizations. Only the upper layer (layer-1) is studied here. (b) LH-CPSS unit-cells used in layer-1 and integrated in a metallic cavity.

This paper is organized as follows. The design and performance of the proposed unit-cell are described in detail in Section II. The measurement set-up and experimental results in reflection and transmission are discussed in Section III. Finally conclusions are drawn in Section IV.

\section{DESCRIPTION OF THE UNIT-CELL AND NUMERICAL RESULTS}

\section{A. Proposed concept and geometry of the unit-cell}

In this section, we illustrate the different steps leading to the final 4-state cell that will be validated experimentally in section III. For the sake of simplicity only two states are considered in this Section. The studied cell (Fig. 1b) is derived from the original Pierrot's design [7]. It consists of a $1 \lambda$-long resonant wire, folded into three segments in a crank-like shape [8]. The transverse segments (along $x$ and $y$-axes respectively) are $3 \lambda / 8$ long and are connected by a $\lambda / 4$ central longitudinal segment (along $z$-axis). The electric currents induced on both transverse segments by a normally incident wave add either in phase or out of phase, depending on the hand of the incident $\mathrm{CP}$ wave. In the proposed design, the cell is embedded in a square metallic cavity (Fig. 1b).

A typical implementation of such a crank is represented in Fig. 2a. It consists of two metallic strips connected by a cylindrical wire. The strips are printed on two thin RT/Duroid 6002 substrates glued with a $3 \mathrm{M}$ bonding film on an $8 \mathrm{~mm}$-thick low-permittivity foam layer, as indicated in Fig. $2 \mathrm{~d}$ and in Table I. The use of thick foam allows reducing impedance mismatching at the dielectric interface [16].

The frequency response computed in reflection with HFSS is represented in Fig. 3 both in amplitude (Fig. 3a) and phase (Fig. $3 b$ ) in blue solid line. In all simulations, we assume that the unit-cell is integrated in a square metallic waveguide (as this will be the case in the measurements) with wave-ports at both ends. Two independent simulations with $\mathrm{TE}_{10}$ and $\mathrm{TE}_{01}$ excitations are required to derive the performance in $\mathrm{CP}$. As expected, the incident LHCP wave is nearly totally reflected at resonance (the reflection coefficient in LHCP, $\left|\Gamma_{\mathrm{L}-\mathrm{L}}\right|$ equals -
$0.7 \mathrm{~dB}$ at $8.5 \mathrm{GHz}$, Fig. 3a). In the following, this phase state is referred to as "State 1 ".

It is well known that, for an incident $\mathrm{CP}$ wave, the reflected phase can be tuned by varying the angular rotation of the reflecting element [17]. As a consequence, another phase state (State 2) can be obtained by introducing a second crank with the appropriate rotation angle (Fig. 2b). In practice, both cranks (cranks 1 and 2) share the same longitudinal segment. This means that i) only additional transverse segments are required, ii) a switching mechanism is needed to connect one of the two pairs of transverse segments to the common longitudinal one. Fig. $2 \mathrm{~b}$ illustrates the top metallization of a possible configuration corresponding to State 2 where the resonant crank is drawn in red, and the pair of disconnected segments is in blue. These disconnected segments behave as parasitic elements whose transparency would be improved, in a reconfigurable implementation, by loading their central part with switches in the off-state. Previous studies [18]-[19] leading to the present work have demonstrated all the required steps to envision the active version of the proposed unit-cell. Only frozen states are considered in this paper: switches in the on- and off-states are replaced by ideal short and open circuits respectively (Fig. 2b). Note that the transverse segments of the resonant crank in State 2 are meandered to accommodate them in the square unit-cell. To ensure that crank 2 resonates at the same frequency $(8.5 \mathrm{GHz})$, a single fixed meander has been added, and the length of the straight part of the segment has been varied until the maximum reflection of LHCP is obtained at $8.5 \mathrm{GHz}$. All dimensions are provided in Fig. 2 (top metallization) and Table I. The transverse segments on the bottom metallization (not shown) have the same dimensions. It is well known that the reflected LHCP wave exhibits a $-2 \psi$ phase-shift if the reflecting element is rotated geometrically by $\psi[16]-[21]$. Here the phaseshift between States 1 and 2 is set to $-2 \psi=-270^{\circ}$ (i.e. $+90^{\circ}$ ). The optimized rotation angle equals $132^{\circ}$ and is slightly different from the theoretical value $\left(135^{\circ}\right)$ because of the imperfect rotational symmetry resulting from the square shape of the cell and the meandering of crank 2 .

Fig. 3 represents in dashed lines the frequency response of State 2 (as depicted in Fig 2b: top metallization). A nearly $90^{\circ}$ phase-shift (compared to State 1) is observed between 8.2 and $8.8 \mathrm{GHz}$ (Fig. 3b), and the reflection loss is lower than $0.7 \mathrm{~dB}$ at $8.5 \mathrm{GHz}$ (Fig. 3a). Two modified configurations are also shown for comparison: in the first one (hollow circles), the parasitic segments are suppressed. In the second one (hollow squares), they are present and short-circuited in their middle. In this last case, it is clear that the frequency response is very different from the other two cases: the phase shift with respect to State 1 is only $50^{\circ}$, and the reflection loss is larger than $7 \mathrm{~dB}$. To conclude, these results demonstrate the benefit of the opencircuit in the middle of the parasitic segments. 


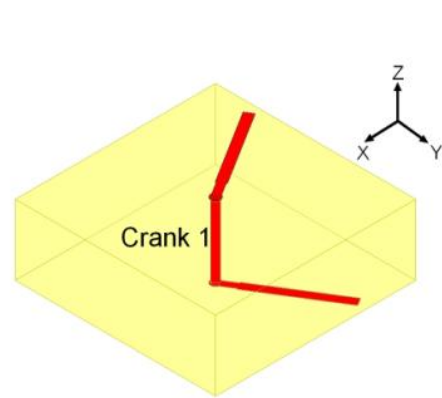

(a) State 1 (3D view)

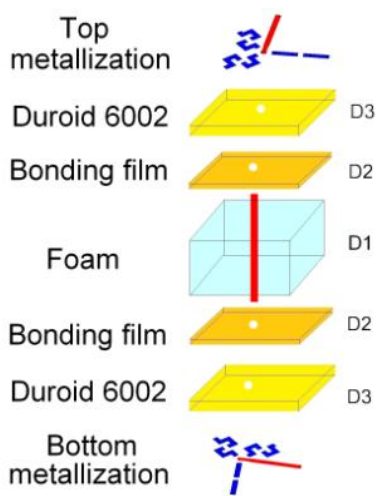

(c) State 1 (exploded view)

Fig. 2. Basic LH-CPSS. The resonant crank is shown in red (a) Resonant crank in State 1. (c) Resonant crank in State 2 with the two parasitic segments of State 1 (in blue). (c) Technological arrangement (without longitudinal segment): $a=22.88 \mathrm{~mm}, W_{g l}=2.1 \mathrm{~mm}, W_{g_{2}}=1 \mathrm{~mm}, W_{a}=1 \mathrm{~mm}, L_{b}=4.75 \mathrm{~mm}$, $L_{a 1}=8.75 \mathrm{~mm}, L_{a 2}=3 \mathrm{~mm}, L_{c}=10 \mathrm{~mm}, \phi_{d}=0.8 \mathrm{~mm}$.

TABLE I

CHARACTERISTICS OF DIELECTRIC LAYERS OF THE UNIT-CELL

\begin{tabular}{|c|c|c|c|}
\hline \hline Dielectric & Description & $\begin{array}{c}\text { Thickness } \\
(\mathrm{mm})\end{array}$ & $\mathcal{E}_{/ / \tan \delta}$ \\
\hline D1 & $\begin{array}{c}\text { Foam } \\
\text { (Rohacell 51HF) }\end{array}$ & 8 & $1.066 / 0.0015$ \\
\hline D2 & $\begin{array}{c}\text { Bonding film 3M- } \\
9485\end{array}$ & 0.1 & $4 / 0.0017$ \\
\hline D3 & RT/Duroid 6002 & 0.127 & $2.94 / 0.0012$ \\
\hline
\end{tabular}

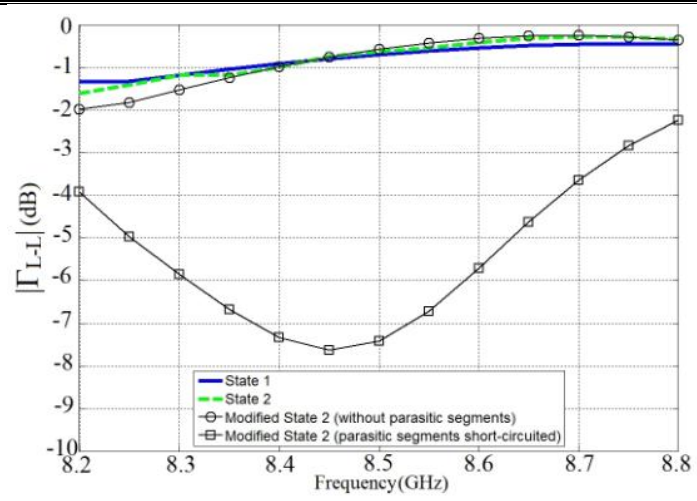

(a)

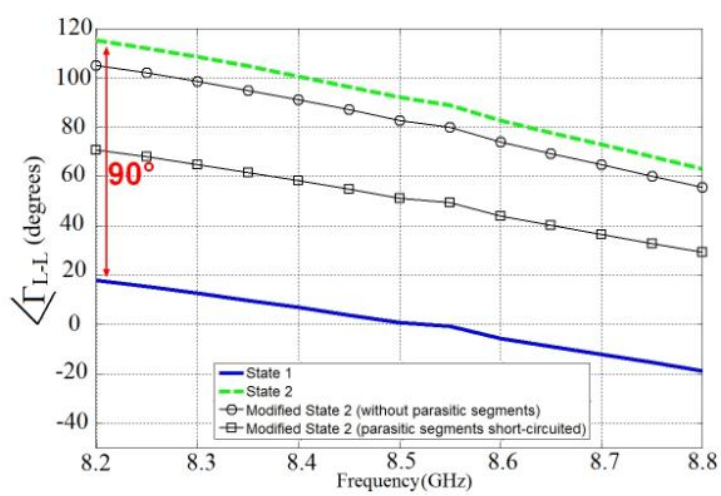

(b)

Fig. 3. Computed reflection coefficients in LHCP for States 1 and 2. (a) Magnitude. (b) Phase.

\section{B. Optimized design and performance}

We have demonstrated in Section II.A that the reflection phase in LHCP $\left(<\Gamma_{\mathrm{L}-\mathrm{L}}\right)$ can be tuned by rotation of the resonant crank and that several phase states can be achieved using additional transverse segments sharing the same longitudinal segment.

This concept has been applied to optimize a multi-crank unitcell providing four different phase states in LHCP at $8.5 \mathrm{GHz}$. The layout of the top metallization for each optimized state is represented in Fig. 4 with the same notations as in Fig. 2 (the connected segments are plotted in red and the blue ones correspond to the parasitic segments). The dimensions of the longitudinal and the transverse segments are the same as in Fig. 2. The rotation angles have been optimized to achieve four phase states with a $90^{\circ}$ phase-shift between two adjacent states. The corresponding values are the following (Table II): $132^{\circ}$ for State $2,48^{\circ}$ for State 3 , and $270^{\circ}$ for State 4 . They are slightly different from the theoretical rotation angles due to mutual coupling and imperfect rotational symmetry of the unit-cell.

The simulated performance for the four possible phase sates in LHCP reflection $\left|\Gamma_{\mathrm{L}-\mathrm{L}}\right|$ (magnitude) and in RHCP transmission $\left|T_{R-R}\right|$ (magnitude) is given in [16] and [21]. The reflection phase responses in LHCP are plotted in Fig. 5 between 8.2 and $8.8 \mathrm{GHz}$; four $90^{\circ}$-spaced phase configurations are obtained with almost the same frequency dispersion. Fig. 6 shows that the RCHP incident wave is transmitted with a nearly constant phase whatever the activated crank. Two quantitative indicators are introduced to evaluate the performance of the cell. The first one is the phase standard deviation $\sigma$ defined as

$$
\sigma=\sqrt{\frac{\sum_{i=1}^{4}\left(\Delta \phi_{i}\right)^{3}}{12 \times 360}}
$$

where

$$
\Delta \phi_{1}=\angle \Gamma_{\text {LHCP }-L H C P}\left(\text { State }_{2}\right)-\angle \Gamma_{L H C P-L H C P}\left(\text { State }_{1}\right)
$$

is the phase difference (in degrees) between the first two states $\left(\right.$ State $_{1}$ and State $\left._{2}\right), \Delta \phi_{i}(\mathrm{i}=2,3,4)$ being defined in the same way from the consecutive phase states. The equivalent bit number 
$N_{b i t}$ is defined by Equ. 3 and is used to assess the overall reflectarray performance by accounting for phase quantization.

$$
N_{b i t}=\frac{\ln \left(\frac{360}{\sqrt{12} \sigma}\right)}{\ln 2}
$$

The second indicator is the average loss for all phase states. The corresponding equivalent bit number [20] of the unit-cell is around 1.95bits. The overall performance of the optimized unitcell is summarized in Table II. This Table shows that the insertion loss for the reflected LHCP is lower than $1 \mathrm{~dB}$ in the $8.2-8.75 \mathrm{GHz}$ range. On the other hand, the RHCP incident wave is transmitted through the LH-CPSS with an insertion loss lower that $1 \mathrm{~dB}$ over a $0.6-\mathrm{GHz}$ range $(6.5 \%)$, and the transmission phase is a nearly identical for all phase states; this constitutes a significant advantage for the complete unit-cell of the dual-CP reflectarray (Fig. 1).

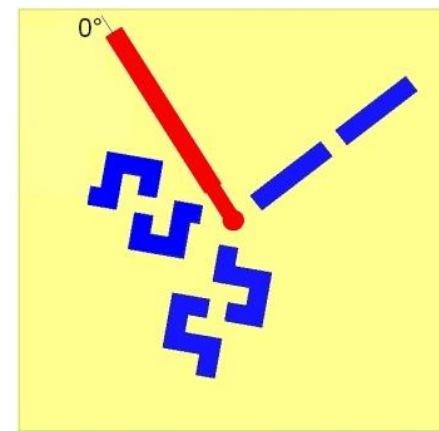

(a) Optimized State 1

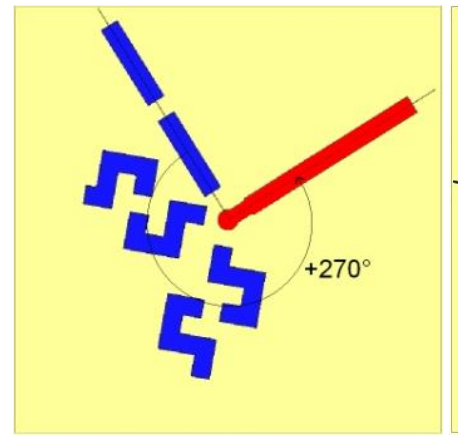

(c) Optimized State 3

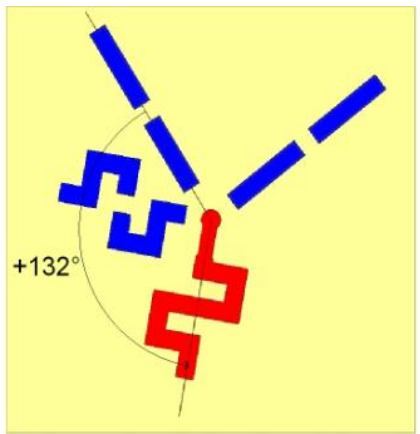

(b) Optimized State 2

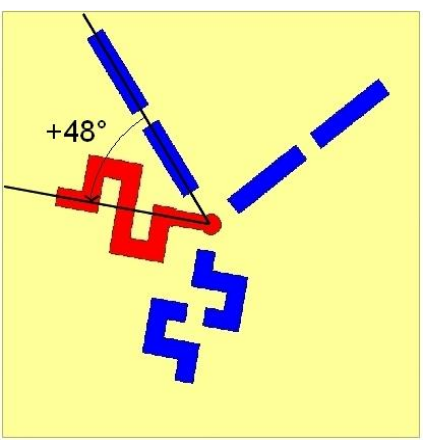

(d) Optimized State 4
Fig. 4. Top view of the four states of the optimized unit-cell.

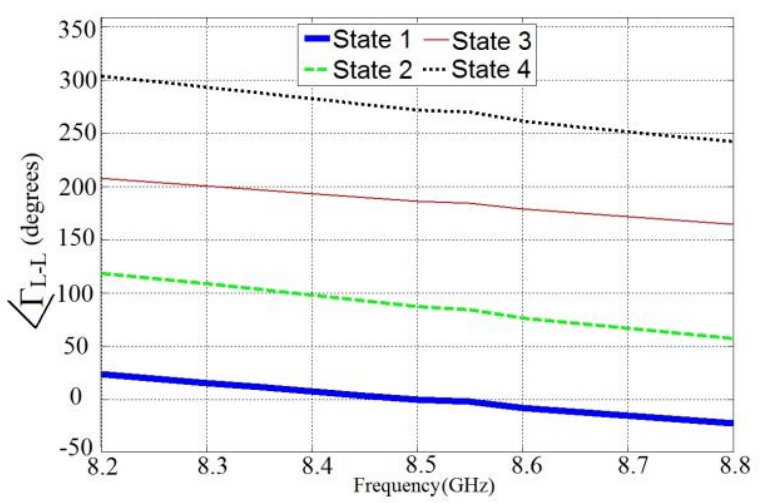

Fig. 5. Simulated phase of the LHCP reflection coefficients $\left(<\Gamma_{\mathrm{L}-\mathrm{L}}\right)$ for the four phase states.

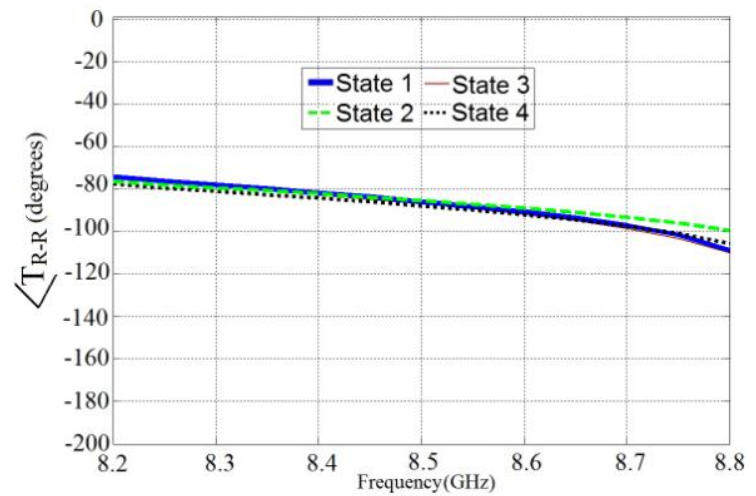

Fig. 6. Simulated phase of the RHCP transmission coefficients $\left(<T_{R-R}\right)$ for the four phase states.

TABLE II

OVERALL PERFORMANCE OF THE OPTIMIZED UNIT-CELL

\begin{tabular}{|c|c|c|c|c|c|}
\hline \hline State & $\begin{array}{c}\text { Theoretical } \\
\text { rotation } \\
\text { angle }\end{array}$ & $\begin{array}{c}\text { Optimized } \\
\text { rotation angle }\end{array}$ & $\begin{array}{c}\text { Reflected } \\
\text { phase at } \\
\text { resonance }\end{array}$ & $\begin{array}{c}\text { BW for loss } \\
\text { lower than } \\
1 \mathrm{~dB} \text { in } \\
\text { LHCP } \\
\text { reflection } \\
(\mathrm{GHz})\end{array}$ & $\begin{array}{c}\text { BW for loss } \\
\text { lower than } \\
1 \mathrm{~dB} \text { in } \\
\text { RHCP } \\
\text { transmission } \\
(\mathrm{GHz})\end{array}$ \\
\hline 1 & $0^{\circ}$ & $0^{\circ}$ & $0^{\circ}$ & 0.585 & 0.6 \\
\hline 2 & $+135^{\circ}$ & $+132^{\circ}$ & $90^{\circ}$ & 0.58 & 0.6 \\
\hline 3 & $+270^{\circ}$ & $+270^{\circ}$ & $180^{\circ}$ & 0.6 & 0.585 \\
\hline 4 & $+45^{\circ}$ & $+48^{\circ}$ & $270^{\circ}$ & 0.6 & 0.6 \\
\hline \hline
\end{tabular}

\section{EXPERIMENTAL RESULTS}

\section{A. Measurement procedure}

Four unit-cells have been manufactured and measured. Each one corresponds to one of the four possible phase states. Fig. 7 represents the fabricated prototype for State 4.

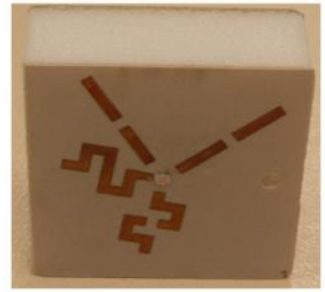

Fig. 7. Fabricated prototype for State 4.

A specific waveguide measurement set-up has been implemented to characterize the unit-cell in dual $\mathrm{CP}$, both in reflection/transmission and in magnitude/phase. The proposed set-up is represented in Fig. 8. The reflection and transmission coefficients are measured in vertical $(\mathrm{V})$ and horizontal $(\mathrm{H})$ polarization using a four-port vector network analyser. Four coaxial-to-WR-90 transitions are connected to each VNA port. Two orthomode couplers (OMT) with a WR-90 input waveguide port and a circular waveguide output port (diameter $23.76 \mathrm{~mm}$ ) are used to separate the $\mathrm{V}$ and $\mathrm{H}$ components of the reflected and transmitted fields. The measured matching level and polarization decoupling of the OMT are better than $30 \mathrm{~dB}$ between 8 and $9 \mathrm{GHz}$. Two taper transitions are employed to transform the circular output waveguide port of the OMT into a square waveguide where the unit-cell to be measured is mounted. 


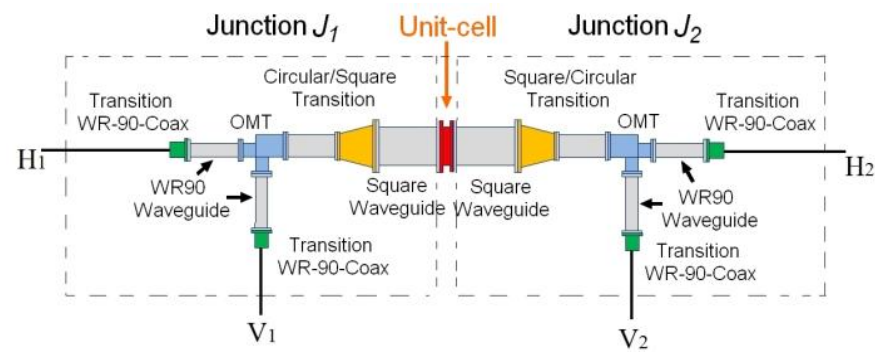

Fig. 8. Measurement set-up.

As illustrated in Fig. 8, the proposed measurement set-up can be seen as two similar junctions connected by a square waveguide where the unit-cell is located. The $T$-matrix of the unit-cell is defined as follows

$$
\left[T_{\text {cell }}\right]=\left[T_{j_{1}}\right]^{-1}\left[T_{\text {meas }}\right]\left[T_{j_{2}}\right]^{-1}
$$

where $T_{j 1}, T_{j 2}$ and $T_{\text {meas }}$ are the $T$-matrix of the junctions (1 and 2) and of the complete waveguide simulator, respectively. $T_{j l, 2}$ are derived from the measured $S$-matrices of the junctions

$$
[S j]=\left[\begin{array}{cccc}
S_{j_{H_{1} H_{1}}} & S_{j_{H_{1} H_{2}}} & 0 & 0 \\
S_{j_{H_{2} H_{1}}} & S_{j_{H_{2} H_{2}}} & 0 & 0 \\
0 & 0 & S_{j_{V_{1} V_{1}}} & S_{j_{V_{1} V_{2}}} \\
0 & 0 & S_{j_{V_{2} V_{1}}} & S_{j_{V_{2} V_{2}}}
\end{array}\right]
$$

in which the coupling between the $\mathrm{H}$ and $\mathrm{V}$ ports is neglected as justified above. A standard waveguide calibration process (using three offset short-circuits) is used in the measurement process. Finally, the $S$-matrix of the unit-cell is deduced from Eqn. (4).

\section{B. Measurements}

The measured frequency responses of the four phase states are represented in Fig. 9 in RHCP and in Fig. 10 in LHCP. Figs. 9 and 10 demonstrate a $5.3 \%$ bandwidth $(0.45-\mathrm{GHz}$ from 8.23 to $8.68 \mathrm{GHz}$ ) with insertion loss lower than $1 \mathrm{~dB}$ in both reflection and transmission. The performance in reflection is even better (Fig. 10a). The slight difference between measurements and simulations might be due to uncertainties in the fabrication process (each state corresponds to a different cell) and to approximations in the de-embedding steps, as discussed previously. Nevertheless, a good agreement is found between the measured and computed [16]-[21] reflection and transmission coefficients in LHCP and RHCP for the four states of the unit-cell. In reflection, the four measured phase responses are almost parallel (Fig. 10b), with a spacing between two adjacent phase states ranging between $74^{\circ}$ and $112^{\circ}$. The maximum deviation in phase between measurements (Fig. 10b) and simulations (Fig. 5) is lower than $30^{\circ}$. The corresponding equivalent bit number, defined in Eqn. (3), equals about 1.9bits and is very close to the theoretical value (1.95bits). Furthermore, the measured magnitudes of the undesired reflection and transmission coefficients for LHCP and RHCP illumination are represented in Fig. 12 and 13. For this first layer, cross-polarization coefficients are about $20 \mathrm{~dB}$ in reflection and $15 \mathrm{~dB}$ in transmission at $8.5 \mathrm{GHz}$.

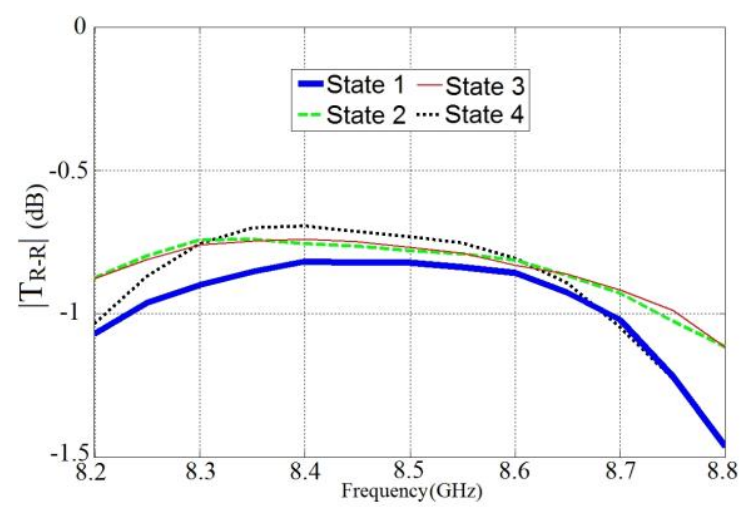

(a)

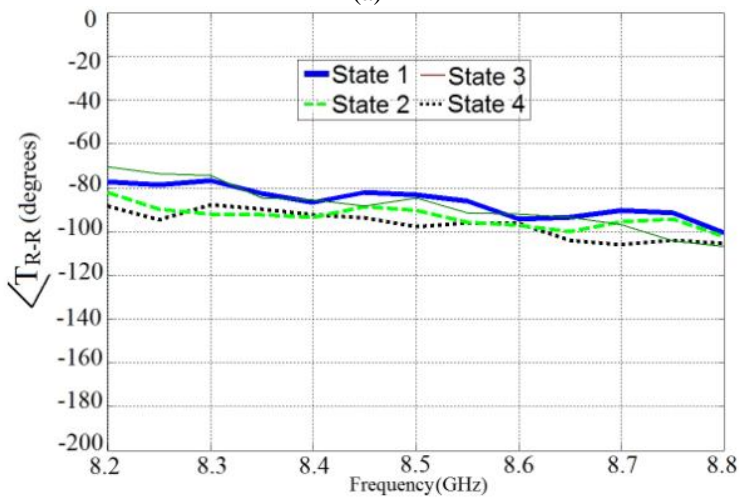

(b)

Fig. 9. Measured transmission coefficients of the four states for a RHCP incident wave. (a) Magnitude. (b) Phase.

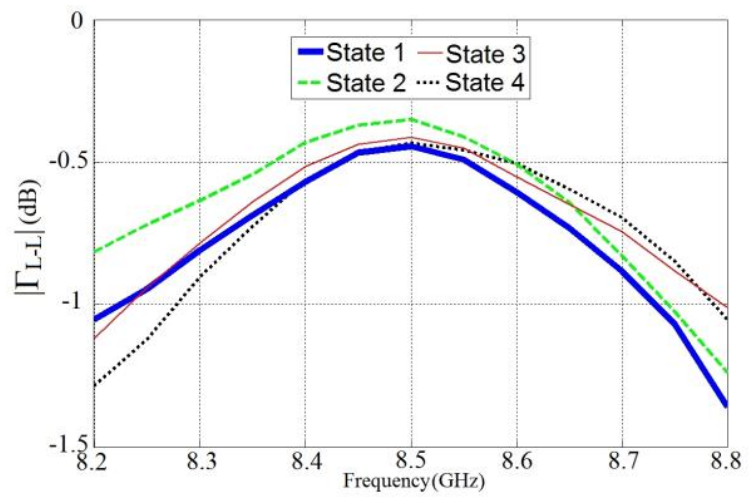

(a)

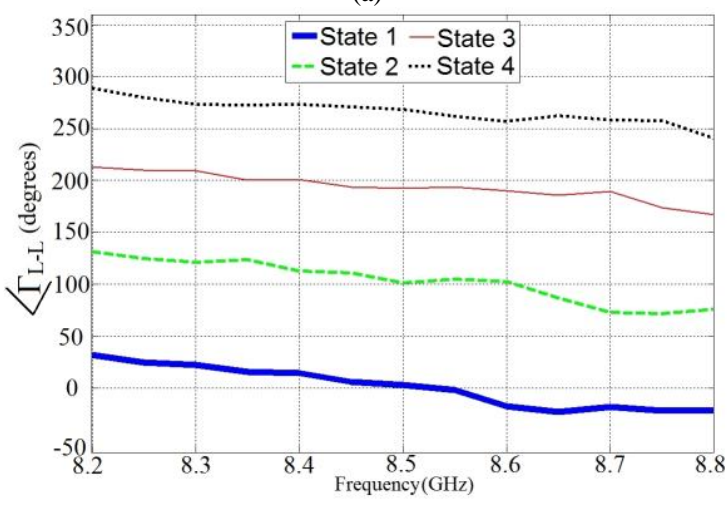

(b)

Fig. 10. Measured reflection coefficients of the four states for a LHCP incident wave. (a) magnitude. (b) Phase. 


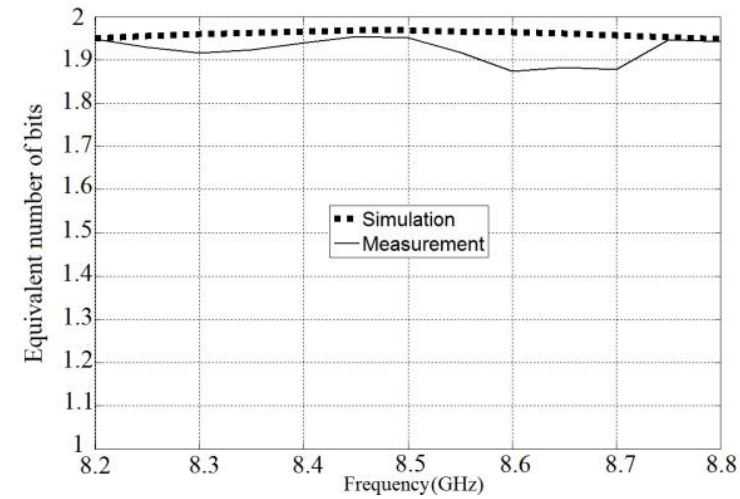

Fig. 11. Measured and simulated equivalent number of bits for a LHCP incident wave.

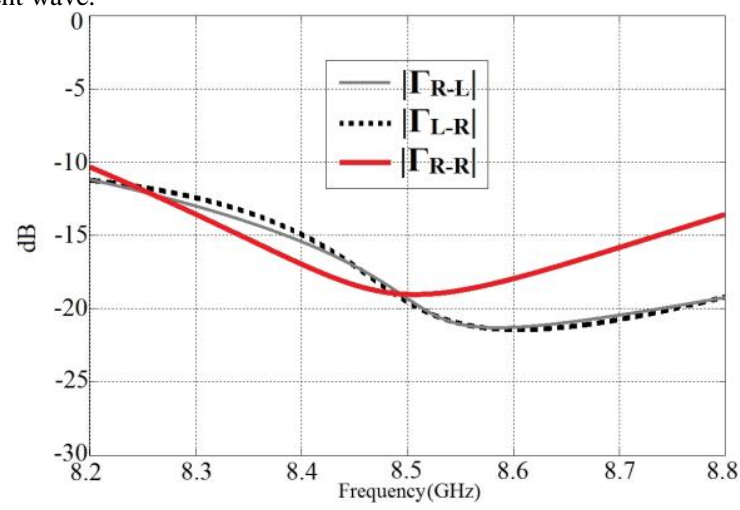

Fig. 12. Measured magnitudes of the undesired reflection coefficients for LHCP and RHCP illumination

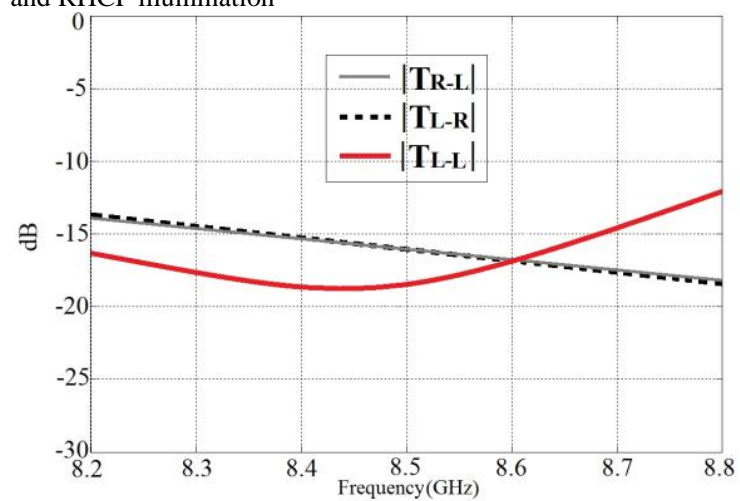

Fig. 13. Measured magnitudes of the undesired transmission coefficients for LHCP and RHCP illumination

\section{CONCLUSION}

A new configuration of reflectarray unit-cell has been studied for a future operation in dual-circular polarization. It consists of a circular polarization selective surface embedded in a square metallic waveguide and made of one resonant crank and parasitic segments, thus leading to a multi-crank unit-cell. The phase response in reflection (LHCP) is controlled accurately by a suitable rotation of the resonant crank.

The proposed unit-cell has been optimized in $X$-band. A specific experimental set-up has been also developed to measure the frequency responses in reflection and transmission, both in amplitude and phase. Experimentally we show that the equivalent number of bits is around 1.9 between $8.2 \mathrm{GHz}$ and $8.8 \mathrm{GHz}$. In transmission (RHCP), the insertion loss is lower than $1 \mathrm{~dB}$ between $8.23 \mathrm{GHz}$ and $8.68 \mathrm{GHz}$. Further developments are now required to combine this LH-CPSS cell with a conventional RHCP cell in order to derive the foreseen dual-CP reflectarray cell.

\section{REFERENCES}

[1] J. Huang and J. A. Encinar, "Reflectarray Antennas", Wiley-IEEE Press, ISBN: 978-0-470-08491-5, Nov. 2007.

[2] M. R. Chaharmir, J. Shaker, M. Cuhaci, and A. Sebak, "Circularly polarized reflectarray with cross-slot of varying arms on ground plane," Elec. Lett., vol. 38, no. 24, pp. 1492-1493, Nov. 2002.

[3] B. Strassner, C. Han, and K. Chang, "Circularly polarized reflectarray with microstrip ring elements having variable rotation angles," IEEE Trans. Antennas Propag, vol. 52, no. 4, pp. 1122-1125, Apr. 2004.

[4] J. H. Wang, "Characteristics of a new class of diode-switched integrated antenna phase shifter," IEEE Trans. Antennas Propag, vol. 31, no. 1, pp. 156-159, Jan. 1983.

[5] E. Martynyuk, J. I. Martinez Lopez, and N. A. Martynyuk, "Reflectarray based on three bit spatial phase shifters: mathematical model and technology of fabrication," Proceedings of the $3^{\text {rd }}$ European Conference Antennas and Propag., Berlin, Germany,23-27 Mar. 2009.

[6] G. A. Morin, "A circular polarization selective surface made of resonant helices," Defense Research establishment, report n. 1269, Ottawa, Canada, Nov. 1995.

[7] R. Pierrot, "Éléments résonnants en polarisation circulaire et réflecteur semi-transparent composé de ces éléments," French patent 89.609, no. $1.512 .598,1966$

[8] J. E. Roy and L. Shafai, "Reciprocal circular-polarization selective surface," IEEE Antennas Propag. Mag., vol. 38, no. 6, pp.18-33, Dec. 1996.

[9] G. A. Morin, "A simple circular polarization selective surface (CPSS)," IEEE Antennas Propag. Soc. Int. Symposium, Dallas (TX), vol. 1, pp. 100-103, May. 1990.

[10] W. V. Tilston, "Polarization selective surface for circular polarization," US Patent 5.053.758, Oct. 1991.

[11] V.F. Fusco and B. Nair, "Circular polarisation selective surface characterisation and advanced applications," IEEE Proc.-Microw. Antennas Propag, vol. 153, no. 3, pp. 247-252, Jun. 2006.

[12] Capozzoli, A. Curcio, C. Delia, G. Liseno, A. Bresciani, and D. Legay, "Fast Phase-Only Synthesis of Faceted Reflectarrays," Proceedings of the $3^{\text {rd }}$ European Conference Antennas and Propag., Berlin, Germany, 23-27 Mar. 2009.

[13] J. Roy, "A new CPSS element," IEEE Antennas Propag. Soc. Int. Symposium, Chicago $(\mathrm{OH})$, Jul. 8-14, 2012.

[14] E. Girard, R. Moulinet, and R. Gillard, "An FDTD optimization of a circularly polarized reflectarray unit cell," IEEE Antennas Propag. Soc. Int. Symposium, San Antonio (TX), vol. 3, pp. 136-139, Jun. 2002.

[15] C. Cheymol, T. Dousset, P. Dumon, M. Labeyrie, and C. Renard, "A Xband electronically scanned reflectarray antenna for space telemetry," Proceedings of the $3^{\text {rd }}$ European Conference Antennas and Propag., Berlin, Germany, 23-27 Mar. 2009.

[16] S. Mener, R. Gillard, R. Sauleau, C. Cheymol, and P. Potier, "A CPSSbased reflectarray cell with reconfigurable capabilities," Proceedings of the $6^{\text {th }}$ European Conference Antennas and Propag., Prague, Czech Republic, 26-30 Mar. 2012.

[17] J. Huang and R. J. Pogorzelski, "A Ka-band microstrip reflectarray with elements having variable rotation angles," IEEE Trans. Antennas Propag, vol. 46, no. 5, pp. 650-656, May 1998.

[18] R. Pereira, R. Gillard, R. Sauleau, P. Potier, T. Dousset, and X. Delestre, "Dual linearly-polarized unit-cells with nearly 2-bit resolution for reflectarray applications in X-band," IEEE Trans. Antennas Propagat., accepted with minor revisions

[19] R. Pereira, R. Gillard, R. Sauleau, P. Potier, T. Dousset, and X. Delestre, "Four-state dual polarisation unit-cells for reflectarray applications," IET Electron. Lett., vol. 46, no. 11, pp. 742-743, 2012.

[20] R. Pereira, R. Gillard, R. Sauleau, P. Potier, T. Dousset, and X. Delestre, "Robust 2-bit dual-linearly-polarised unit-cell for reflectarray 
applications," Proceedings of the $5^{\text {th }}$ European Conference Antennas and Propag., Rome, Italy, pp. 1488-1490, 11-15 Apr. 2011.

[21] S. Mener, R. Gillard, R. Sauleau, C. Cheymol, and P. Potier, "Design of a CPSS-based reflectarray cell with controllable reflected phase for dual circularly polarized reflectarrays," Proceedings of the $15^{\text {th }}$ International Symposium on Antenna Technology and Applied Electromagnetics, Toulouse, France, 25-28 Jun. 2012. 